\title{
Selecting a suitable Ballast Water Treatment System for a small general cargo vessel
}

Alan Clare. B.Eng., MSc. ${ }^{a}$

${ }^{a} \mathrm{C} / O$ Corrib Ship Management Ltd, Taney Hall, Eglinton Terrace, Dundrum, D14, ROI.

\section{ABSTRACT}

The main questions which will be addressed in this paper are; which ballast water treatment system (BWTS) should be fitted to a fleet of small general cargo ships that are trading in Northern Europe, including the Baltic Sea, and how will the implementation of the Ballast Water Management Convention (BWMC, herewith "the Convention") will affect the engine room crew? There is a large capital cost in the purchasing and fitting of such a system, and as the vessels in question have some special requirements, such as operating in very cold weather and having small engine rooms, the correct system must be chosen. As the small engine room crew, consisting of a chief engineer and an oiler, must be able to operate, maintain and repair the system, the chosen system will impact on their working life while onboard these vessels.

To answer the research questions, all the chief engineers employed by the Company and a number of shore superintendents from other shipping companies, involved in the management of small general cargo ships were surveyed using questionnaires. Their responses were then analysed and conclusions drawn from this analysis. The criteria required to choose a ballast water treatment system was narrowed down during the research, and then used to find the most suitable system for the company vessels.

A small number of systems currently in production from well-known manufacturers were evaluated during this process. Following evaluation of the systems using the responses from the respondents, the most suitable system for the company vessels was identified and chosen. The need for training was also identified to successfully operate and maintain the system, and to reduce any additional stress that may be experienced by the crew due to the BWMC.

The research also contains a review of the BWMC, and a comparison with measures brought in by the United States Coast Guard (USCG), which include the transfer of harmful aquatic organisms and pathogens, (HAOP) by merchant vessels from area to area by other methods that are ignored by the BWMC. It also considers the long-term health effects on the crew and marine ecosystem from treated ballast water using some types of treatment systems. The report of the survey provides scope for a more informed decision making process when choosing a BWTS for a small general cargo vessel. However, in addition, the process can be applied to any type of vessel as many of the issues encountered will be the same regardless of size and trading pattern.

Keywords: Ballast Water treatment system, Salinity, General cargo vessel, Turbidity

\section{Introduction}

The author is employed as a technical superintendent for a small shipping company that owns and operates a fleet of four general cargo vessels, ranging in size from 3500 DWT to 
6000 DWT. These vessels operate mainly in the Baltic Sea and around Northern Europe, but also trade in the Mediterranean Sea occasionally. To meet the requirements of the 2004 BWMC, the company must supply and fit a ballast water treatment system to each vessel. To assist in the decision making, several treatment systems were evaluated under the following criteria: water temperature, salinity, turbidity, size and electrical requirement, and were evaluated by the engineers onboard the company vessels. Further areas were surveyed concerning training, health risks and hours of work. The data gathered from the surveys will be analysed by evaluating each question separately. These findings will be discussed and the most suitable system will be chosen as the most suitable for the fleet, as the ships are all small general cargo ships of roughly the same size which operate in the same trading area.

\section{The Ballast Water Management Convention 2004.}

The International Maritime Organization (IMO) has drawn up the Ballast Water Management Convention 2004, (BWMC), to reduce the transfer of invasive species of aquatic organisms, after transportation in ships ballast water, to a non-native habitat where they can damage the existing ecosystems. To meet Regulation D-2, Ballast Water Performance Standard, which sets the amount and size of viable organisms discharged per cubic metre of ballast water, a ballast water treatment plant is required to be installed on most ships.

While the Convention will govern most of the world's seas, the United States Coast Guard have their own rules on this subject, which must be adhered to in their waters. The American Bureau of Shipping (ABS) highlights these in their publication, "Ballast Water Treatment Advisory 2014", (ABS, 2014). It should be noted here that while this does not affect the company usually, as the company vessels do not transit the Atlantic Ocean, the vessels could receive a trans-Atlantic voyage at any time. Another point to note is that the USGC has specific rules for the removal of "fouling organisms from the vessel's hull, piping and tanks on a regular basis and disposing of any removed substances in accordance with local, State and Federal regulations" (ABS, 2014). Lawal (2011) points out there are other ways that HOAP can be introduced, including "hull fouling, cargo, and other areas of the ship". The USGC recognises that there are other vectors of transmission for invasive species and provides for this, however the BWMC concentrates only on the treatment of ballast water and removal of sediments from ballast tanks.

\section{Method}

The research took the form of a qualitative case study undertaken on the small shipping company which the researcher is employed by. A case study is defined as a "research strategy that involves the empirical investigation of a particular contemporary phenomenon within its real life context, using multiple sources of evidence." (Saunders, 2012). The investigation into which ballast water treatment system the company should install and how to lessen the impact of implementation of the BWMC on the crew is certainly a contemporary issue as the Convention will be in force later this year. The case study will be treated as a single case study because it is dealing with a "typical" (Saunders, 2012) issue. There are many small general cargo ships trading around Europe, and each of them will need a ballast treatment system. As it is a case study, more than one method of data collection was used and the results were analysed. 


\section{Vessel requirements}

As the vessels have a wide range of operational areas, a system that can operate in various ranges of salinity, temperature and turbidity is required.

The vessels are small leaving a limited amount of free space available, so the required treatment plant will need to be as small as possible. Another requirement is that the electrical load be as small as possible. The vessels have two diesel alternators, and all port operations have to be conducted using one diesel alternator, to allow for redundancy. In port the generator must be able to handle ballasting operations, hatch crane operations, the normal ships load and the extra load of the treatment plant.

To reduce any possible delays during ballasting operations, the chosen treatment plant would match the maximum flowrate of both ballast pumps.

\section{Questionnaire}

Once these criteria were identified they were put to the Company chief engineers and several superintendents, who were experienced with the type vessel, using a questionnaire. All the respondents, both sea going engineers and the shore side superintendents, are or were qualified Marine Engineer Officers under the IMOs Standards of Training, Certification and Watchkeeping 1995 (STCW 95) at management level. The decision to survey engineer officers only was made as it will be engineer officers that will be responsible for the treatment system.

The questionnaire also had questions about how the Convention could affect the crew, these included potential health risks from ballast water, and if the working hours of the chief engineer would increase. They were also queried on whether training is required with the plant, and how important low maintenance and automation was. As the chief engineers are not native English speakers a 3 point Likert scale was used because 'if you know your respondents can only respond accurately to a three point rating, then it is pointless to have a finer rating scale' (Saunders, 2012). The superintendents will have interviewer-completed questionnaires and Chief Engineers the self-completed questionnaires.

\section{Data Results}

The results from the questionnaires were received back from the respondents and these were tabulated to see the relevance of each of the criteria. 
Figure 1. Questionaire answers concerning the operational requirements of the treatment plants.

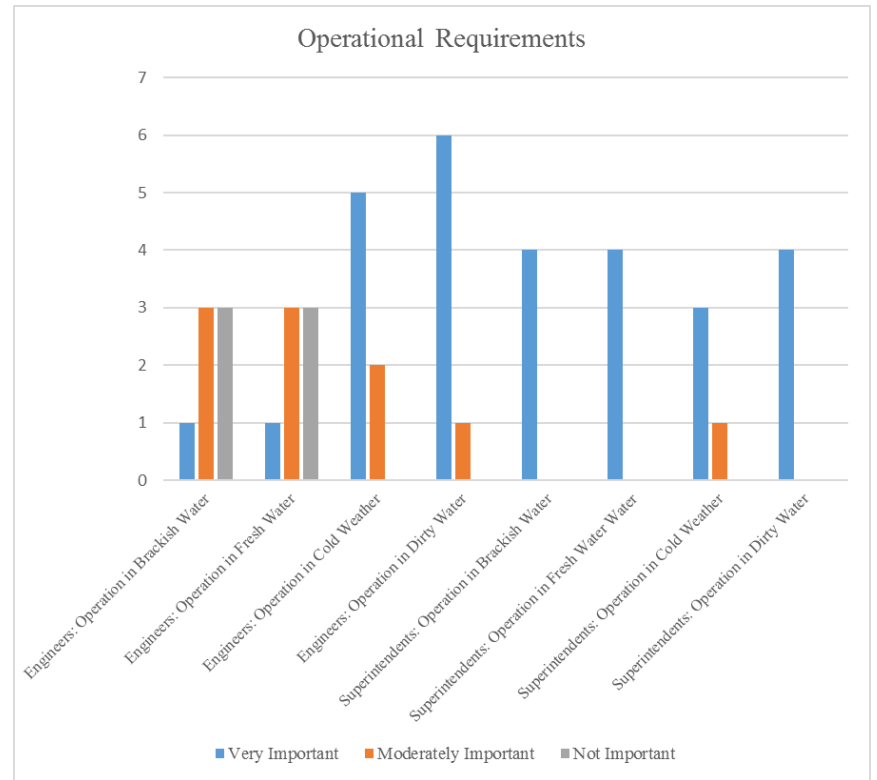

Figure 2. Questionaire answers to the questions on small sise and small electrical power requirements for the treatment plant.

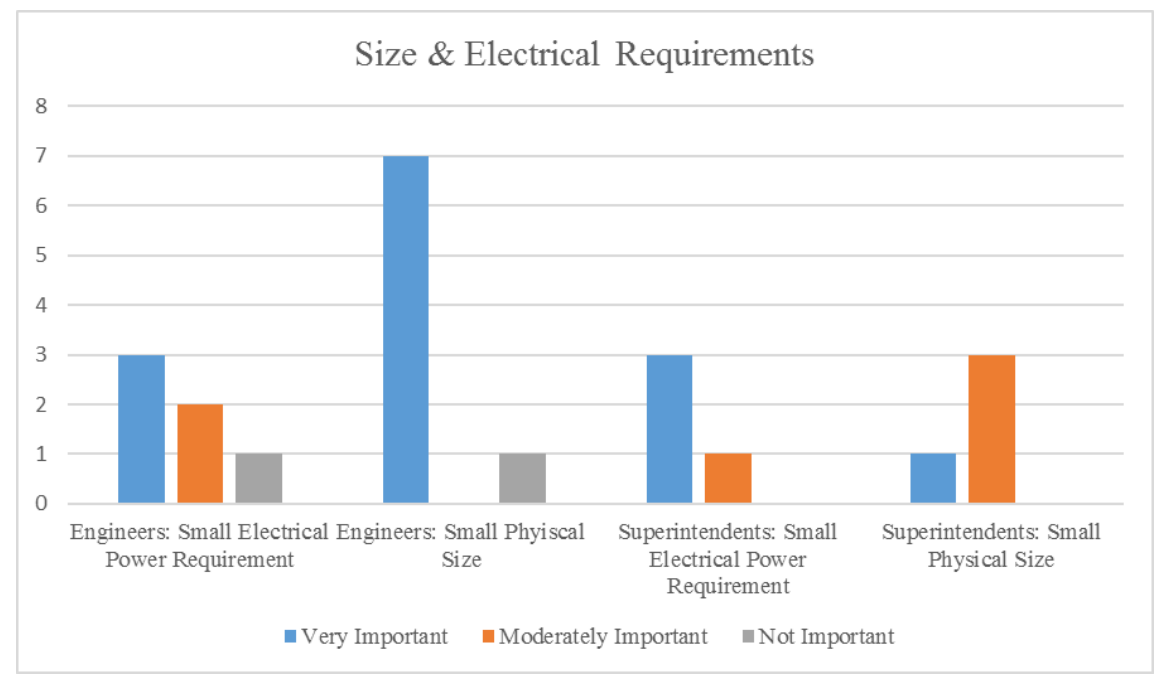


Figure 3. Responses to the questions concerning potential health risks from treated ballast water.

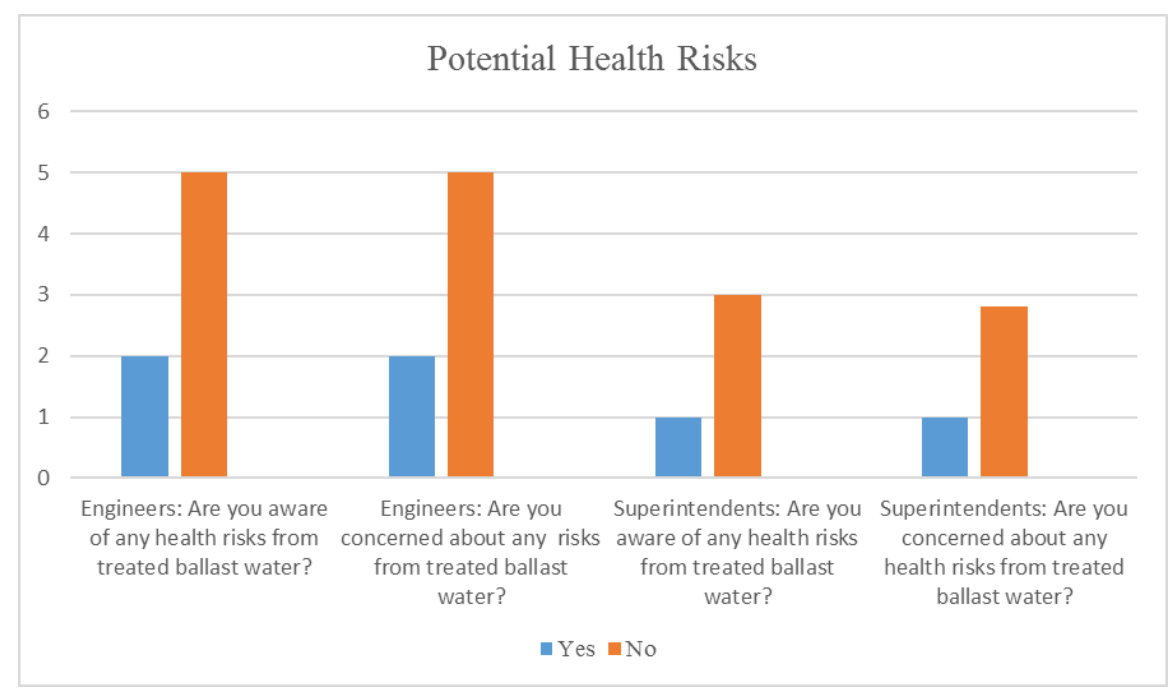

In order to clarify the decision making process, it was decided to use weighting on each of the deciding factors on each plant. The deciding factors are from the surveys are:

- Operational Considerations, such as operation in cold water, in brackish water, in fresh water and dirty (turbid) water.

- Physical Size and Electrical Requirement

- Health Risks

- Automation and Maintenance

Each factor will be weighted from 1 to 3 , as there are three systems, with 1 being the most desirable and 3 the least desirable. At the end of the weighting, these numbers will be added up and the lowest score will show the plant most suited to the company vessels.

If there is a factor which is the same for 2 or more plants, then each plant will score 1 . If there is no information on the factor, then the plant will score 3 , as the plant must work in all operational conditions the vessel is likely to face.

The results were then tabulated and the most suitable machine chosen, please see Table 4. The treatment systems are manufactured by well-known marine equipment manufacturers but they have not been named for the purposes of this paper. Two UV plants of varying characteristics and one electro chlorination plant were evaluated.

Capital costs have been ignored for the purposes of this paper as the other criteria were deemed to be more important. Installation costs were assumed to be similar for all plants. All plants were IMO type-approved.

\section{Analysis}

\section{Turbidity}

Most of the ports in Europe are tidal, and many have a large range between low water and high water. A common characteristic of these tidal ports is a "mobile region of high 
suspended sediment concentration (SSC) known as a turbidity maximum (TM)." (Mitchell, 2013). This region can move up and down the estuary and vary due to the condition of the tide and the amount of rain fall in the local area. (Mitchell, 2013) As a result the turbidity can change in the same port over a number of hours depending on the tide. Due to this fact, the plant must be able to handle turbidity within a reasonable limit. EC Plant 1 is not effected by the turbidity, while both the UV Plants do have a limit of what they can treat in turbid water.

\section{Salinity}

The salinity of sea water varies, with the Baltic Sea having very low salinity. This was an issue for EC Plant 1 as it requires some salinity to operate correctly, and while it can use previously ballasted water if the salinity is high enough, it as a concern as the company vessel can stay in the Baltic area for months at a time, and they could be occasions when there was no suitable ballast on board. UV Plant 1 needs a specified filter to cope with low salinities. UV Plant 2 has no stated difficulties.

\section{Temperature}

Temperature was another important issue, as the ships can operate in the Baltic in the Winter. The EC Plant 1 can operate down to $-2^{\circ} \mathrm{C}$, while the only restrictions on the UV Plants is that there is no ice or slush entrained in the ballast. It is assumed the pump filter will remove any slush or ice. It is worth noting that the company has recently begun fitting thermometers on the ballast pumps to investigate the temperature of water in the Baltic in Winter.

\section{Size}

EC Plant 1 is quite large, with the UV Plant 1 being slightly smaller but UV Plant 2 is the smallest of the three. The footprint only was examined as there is generally enough head room available about the footprint.

\section{Electrical Requirements}

With regards to the electrical power requirement, EC Plant 1 had the highest requirement for electrical power, with UV Plant 1 having a range, depending on the turbidity of the water being treated. UV Plant 2 had the lowest requirement.

\section{Automation and Maintenance}

All plants are fully automatic, while both UV Plant $1 \& 2$ had low maintenance levels. EC Plant 1 had a medium level in comparison to the other two.

\section{Training and stress}

All the manufacturers in question offered training to varying degrees for their treatment plants. The respondents stated that training was required but there was some difference of opinion on to what level of training would be needed. Apart from training being required to operate the treatment system correctly, a further benefit from training is that it can help to reduce stress amongst the crew, as the International Committee on Seafarers Welfare, ICSW, (ICSW, 2015) state that "change, and how it is managed" (ICSW, 2015, p4) can contribute or be the cause of stress on board. It will also help to reduce any resistance to change. (Williams, 2009). The training can "provide information" (Williams, 2009, p61) and 
also "encourage involvement" (Williams, 2009, p61), both of which will reduce the resistance to change.

\section{Hours of work}

All respondents believed the working hours of the chief engineer will be likely to increase due to the implementation of the Convention. This has caused some concern as being required to work extra hours can add to fatigue, which is listed as an "important occupational health \& safety issue" (MSC, 2001), extra hours can cause the Hours of Rest to be breached. This is very serious should it occur. Installing a plant with low maintenance and full automation will help to reduce this risk.

\section{Health risks}

Most respondents were not aware of any potential health risks from treated ballast water. Most types of treatment system also discharge disinfection by-products (DBPs) with the treated ballast water. Although DBPs are present in UV treated water, they are very much reduced. One difficultly with the subject of DBPs formation in treated ballast water is that the assessment is "limited by the lacking completeness and quality of available information" (Banerji et al, 2012).

The ship's owner has made a preference that all health risks should be taken seriously by the company and that the environmental impact of the company should be lessened if it is possible within reason (McEvoy, 2015), therefore the preference will be towards the UV systems to reduce any long-term health risks to the ship's crew and general public. However, it is worth noting that even recently "there has been very little systematic research on the levels of DBPs formed during ballast water treatment” (Banerji et al., 2012).

\section{Conclusion}

The implementation of the IMO Ballast Water Management Convention will begin on the $8^{\text {th }}$ September 2017, and the requirement to have a BWTS on each vessel will come after that. The company has started the process of implementation already with this research, and it has provided them with an insight into the process of choosing the correct plant for the company vessels, while also introducing the topic to the ships crews across the fleet.

The criteria were evaluated and the company has decided UV Plant No 2 will be the best option to be fitted on the company vessels as it fulfils the criteria the most. It is the smallest, has the lowest electrical power requirement, with the ability to operate in in all salinities, temperatures and turbidity the vessels are likely to encounter. It is fully automatic with low maintenance requirements. 
Table 1. The results of the analysis were inserted into a table and the scores added together to give a final total. The lower the score the more suited the system is to the company vessels, per the criteria.

\begin{tabular}{|l|l|l|l|l|l|l|l|l|l|}
\hline System & Size & $\begin{array}{l}\text { Electrical } \\
\text { Require }\end{array}$ & Salinity & $\begin{array}{l}\text { Water } \\
\text { Temp }\end{array}$ & Turbidity & Automation & Maintenance & $\begin{array}{l}\text { Health } \\
\text { Risks }\end{array}$ & Total \\
\hline $\begin{array}{l}\text { EC } \\
\text { Plant 1 }\end{array}$ & $\mathbf{3}$ & $\mathbf{2}$ & $\mathbf{2}$ & $\mathbf{1}$ & $\mathbf{1}$ & $\mathbf{1}$ & $\mathbf{2}$ & $\mathbf{2}$ & $\mathbf{1 4}$ \\
\hline $\begin{array}{l}\text { UV } \\
\text { Plant 1 }\end{array}$ & $\mathbf{2}$ & $\mathbf{3}$ & $\mathbf{1}$ & $\mathbf{1}$ & $\mathbf{2}$ & $\mathbf{1}$ & $\mathbf{1}$ & $\mathbf{1}$ & $\mathbf{1 2}$ \\
\hline $\begin{array}{l}\text { UV } \\
\text { Plant 2 }\end{array}$ & $\mathbf{1}$ & $\mathbf{1}$ & $\mathbf{1}$ & $\mathbf{1}$ & $\mathbf{3}$ & $\mathbf{1}$ & $\mathbf{1}$ & $\mathbf{1}$ & $\mathbf{1}$ \\
& & & & & & & & & \\
\hline
\end{tabular}

\section{Acknowledgement}

I would like to thank Mr. McEvoy of Corrib Ship Management Ltd for his continued support. I would like to thank my wife, Emma, and sister Jane for their proof reading skills.

\section{References}

American Bureau of Shipping. 2014. Ballast Water Treatment Advisory 2014, Available at: http://ww2.eagle.org/content/dam/eagle/publications/2014/BWTAdvisory14312rev3.pdf (Accessed: 23/08/15)

Banerji S et al. 2012. Disinfection by-products in ballast water treatment: An evaluation of regulatory data. Water Research, No 46 2012, p4884

https://doi.org/10.1016/i.watres.2012.05.034

International Committee on Seafarers' Welfare. 2015. Guidelines for Mental Care Onboard Merchant Ships, Available at: https://www.seafarerswelfare.org/images/shopfiles/mentalcare/mental care a4 guidelines 12pp.pdf (Accessed: 15/11/15)

Lawal S. 2011. Ballast Water Management Convention, 2004: Towards Combating Unintentional Transfer of Harmful Aquatic Organisms and Pathogens. Master Thesis.

Dalhousie University available at:

http://dalspace.library.dal.ca/bitstream/handle/10222/14184/Lawal,\%20Sabitiyu\%20Abosede, \%20LLM,\%20Law,\%20August\%202011.pdf?sequence=1 (Accessed: 27/08/15.)

Maritime Safety Committee. 2001. Guidance on Fatigue Mitigation and Management, available at:

http://www.imo.org/en/OurWork/HumanElement/VisionPrinciplesGoals/Documents/1014.pdf

(Accessed: 8/12/15)

McEvoy J. 2015. Email to Alan Clare, 21/12/15

Mitchell SB. 2013. Turbidity Maxima in Four Macrotidal Estuaries. Ocean \& Coastal Management Volume 79: p62-69 https://doi.org/10.1016/i.ocecoaman.2012.05.030 Saunders $\mathrm{M}$ et al. 2012. Research Methods for Business Students, $6^{\text {th }}$ Ed, Pearson, London Williams L. 2009. Strategic Management, Dorling Kindersley, London. 